\title{
Achieving parametric transparency in model-based factory planning
}

\author{
Peter Burggräf $^{1} \cdot$ Thomas Bergs $^{1} \cdot$ Matthias Dannapfel $^{1} \cdot$ Andreas Korff $^{2} \cdot$ Matthias Ebade Esfahani $^{1}$ (1) \\ Antonia Splettstoesser ${ }^{1}$. Julius Steinlein ${ }^{1}$
}

Received: 28 September 2020 / Accepted: 3 December 2020 / Published online: 8 January 2021

(c) The Author(s) 2021

\begin{abstract}
The planning of new factories, as well as the re-planning of existing factories, has become more frequent due to increasingly changing business requirements, as for example shorter product life cycles and Industry 4.0. A higher number of involved planners and the resulting high amount of planning information strongly require coordination. In this context, the importance of Building Information Modeling (BIM) in factory planning rises as it provides a method of integrated building planning and planning validation by means of 3D software and object-oriented modelling. However, despite the use of BIM, there are still major interface problems in factory planning that cannot be solved by the still manual plausibility checks of non-geometrical planning information. To enable automatic checking of planning results, thereby improving the BIM-based factory planning process, machine-readable explication of the parametric dependencies are required between different planning fields such as production planning and building planning. The goal of this paper is to show parametric and thus non-geometric dependencies that exist between the sub-models of BIM-based factory planning in such a way that software agents can automatically evaluate this design information. Within the planning interface between production planning and building planning, the paper focusses on the particular exchange between the planning of the manufacturing system and the planning of a cutting fluid pump. With the involvement of domain experts from factory planning, systems engineering and production engineering, we as the authors have managed to develop a coherent system of block diagrams, constraint diagrams and parametric diagrams that explicate the focused interface in a machine-readable manner. We believe our accomplishments are an essential element for completely automated planning validation in BIM-based factory planning and general object-oriented modelling in the future.
\end{abstract}

Keywords Factory planning $\cdot$ Systems engineering $\cdot$ Cutting fluid $\cdot$ Building information modelling

\section{Introduction}

The time and cost pressure of factory planning projects has considerably increased in recent years. On a first level, this can be explained by shorter product life cycles and the rising number of involved stakeholders in factory planning projects. Current factory planning approaches try to address these challenges by means of Building Information Modelling (BIM) as it is designed to ensure a continuously

Matthias Ebade Esfahani

m.ebade-esfahani@wzl.rwth-aachen.de

1 Laboratory for Machine Tools and Production Engineering (WZL), RWTH Aachen University, Campus-Boulevard 30, 52074 Aachen, Germany

2 Parametric Technology GmbH, Edisonstraße 8, 85716 Unterschleissheim, Germany digital planning chain, central data management, and automatic design validation. [1] However, also BIM-based factory planning projects still report increased costs and significant time delays. In an expert study of the Laboratory for Machine Tools and Production Engineering (WZL) of RWTH Aachen University, the researchers had achieved to attribute this problem mainly to the inability to check planning deliveries from different specialties for congruence (e.g. between manufacturing system planners and MEP planners (Mechanical, Electrical, Plumbing)). [1] In other words, BIM coordinators and BIM managers face the challenge of exhaustively and correctly validating whether the planning parameters of a manufacturing system fit to the system parameters that the MEP planner has designed. This is because BIM has been targeted mainly for private housing, public constructions and office buildings. [2] Factory planning, however, extends building planning by the 
additional field of manufacturing systems planning. The number of planners hence rises, and the planning focus is shifted away from the building as the foremost goal of factory planning is the value-adding process. [3] Factory planners often work as the general planner of a factory project bearing a legal responsibility towards the building owner regarding the planning services. With the advent of BIM, they often take up the part of the BIM manager as well.

The planning of the factory and its value-adding processes directly depend on the product and the effort required to produce it. [4] This becomes particularly clear when considering an industry which needs to deliver precisely manufactured components such as the aviation industry. [5] Structural and engine components of airplanes are produced by accurate manufacturing processes along with the applicable infeed of cutting fluid - the pump of which and all feed pipes are planned by the MEP planner or by a planning department of the pump supplier. It needs to be emphasised that, in contrast to the planning of Heating, Ventilation, Air Conditioning (HVAC) or electricity, the design of cutting fluid pumps is not part of the standard planning domains of an MEP planner. Nevertheless, according to our experience, this task is often additionally commissioned to MEP planners who then also carry out all pipeline and duct planning.

Already existing solutions which can validate planning deliveries-such as Solibri Office-are mainly implementation-oriented, and have pre-defined rule sets which do not suffice for factory planning. They do only allow the construction of one's own rules in a rather complex, non-intuitive way (black box method).

The objective of this study was therefore to solve the problem of manual planning parameter checking in factory planning by establishing machine-readable parametric connections between manufacturing planning and MEP planning with a focus on cutting fluid. The vision behind that is an automatic validation of factory designs in the future.

We, as the authors and researchers of this paper, used OMG Systems Modeling Language (SysML) to develop a model which can be used by software developers to program automatic control checks into software, or by software agents to directly perform automatic design checks. As a research consortium of factory planners, manufacturing experts and system engineers, we conducted mutual expert interviews to develop the model-based system.

Section 2 explains the study's research methodology and gives an introduction into SysML modelling. The results of our study are set out in Sect. 3 by explaining the different parts of the developed SysML-model at the interface between manufacturing systems planning and MEP planning. Section 4 discusses the obtained results regarding underlying assumptions and limitations of the study. The paper concludes with an outlook of how our results raise the efficiency of BIM-based factory planning.

\section{Research methodology}

The research methodology of the study was split into two parts. The first part of the methodology are expert interviews. They were used to examine information that is to be exchanged and validated in the focussed interface between MEP planning and manufacturing systems planning. The second part of the methodology is SysML which was used to express the information in a machine-readable manner.

The study was performed in a research consortium of four people: two experts from factory planning and manufacturing systems planning (Chair of Production Engineering of RWTH Aachen University), one expert from the field of manufacturing process design and cutting fluid supply (Chair of Manufacturing Technology of RWTH Aachen University) and one expert from the field of Systems Engineering (PTC). In this consortium, we (the research consortium which is also author of this paper) conducted mutual in-depth interviews where every participant was both interviewer and interviewee over the course of the study. [6] We chose this approach as we intended to give every expert the perspective of the overall project leader, thereby formulating requirements from his point of view, that is, from his or her field of expertise. The factory planners hence took the perspective of production planning, and set requirements for the planning procedures of the other two parties. Likewise, the manufacturing process planners focussed on planning a cooling fluid pump for a specific manufacturing process. The expert of Systems Engineering interviewed the other two parties in order to be able to establish a machine-readable Systems Model as unambiguously as possible.

The interviews were conducted within a timeframe of only three weeks (March 2020) which enabled every interviewer to integrate insights from his or her previous interview in which he or she had taken the role of the interviewee. As a summary, the following classification criteria of the mutual interviews as the underlying qualitative research method can be outlined [7]:

- Level of structure: The interviews were semi-structured. In other words, every interviewer prepared a questionnaire as a guideline which at the same time left enough leeway to focus on specific response parts in detail.

- Number of interviewees/interviewers in one interview: The interviews were conducted one-on-one.

- Type of interview contact: The interviews were conducted in either personal conversations or video conferences. 
- Type of respondents: All participants were experts in their field with at least 2 years of professional experience.

The transcripts of the interviews were analysed using coding technique and qualitative content synthesis following the approach of HsieH. [7, 8] After the interviews, one specification sheet was created for each of the three expert domains containing domain-specific requirements. The mono-perspectivistic requirements lists of each field were then linked to each other and consolidated to create a machine-readable formalisation of the interface between cutting fluid demand and manufacturing systems planning. One outcome of the superimposition of these three specification sheets was the decision to use the SysML as the second part of the research methodology that underlies this study.

Automatic checking of planning information involves developing either a complete software, a software plug-in, or at least a logic construct that is readable by software agents. In software development, it has been common practice to use model-based approaches because document-centred approaches often include technical project information being distributed across many documents. In model-centred development, all information is kept centrally in one model—very similar to BIM where all sub-models of the building are also maintained in a central model. [9]

Model-based approaches enable planners to already use formalised structures at an early development stage so that partial simulations can be run. Moreover, the object-oriented nature of many model-based languages make it possible to merge identicalities and similarities, to prevent redundancies, and to close gaps in the model. Furthermore, the logic of a model-based system model can be validated by concrete instantiation and then be used for actual use cases. Therefore, model-based system approaches were also evaluated to be appropriate for this study in order to express logic relationships between MEP planning and manufacturing system planning for automatic planning validation.

In order for these models to be understandable, the notations must be known by all participants and should therefore follow a certain standard. Unified Modeling Language (UML) is already widely used in software development. [10] Yet, it is only suitable for system modelling to a limited extent. SysML is an extended subset of UML2.0 having an $80 \%$ of syntactic and $90 \%$ of semantic overlap with UML2.0. [11, 12] Nevertheless, it uses modified versions of UML's structural diagrams and activity diagrams, and, more importantly, introduces two additional diagrams: requirements diagrams for visual requirements traceability and parametric diagrams. [9] The interviews revealed strong dependencies between MEP planning and manufacturing systems planning, including mathematical or at least discrete parametric connections. In order to model those connections and resulting planning constraints in an accurate way, SysML was chosen as the modelling language of this study.

\section{Research results}

The knowledge acquired throughout the interviews was combined and transferred to a SysML-model. We have found that the dependencies of the planning activities can be adequately represented on a first level with SysML's block and parametric diagrams. On the basis of these diagram types, we have built the overall model which is divided into four areas (see Fig. 1):

1. Production-based parameters (Area 1): In this area, parameters derived directly from the production process are used to determine the demand and specifications for cutting fluid applications.

2. Factory planning properties (Area 2): Area 2 focuses on machine tool properties which are subject to planning activities of manufacturing system planners.

3. Properties of a cutting fluid pump and connection constraints (Area 3): Area 3.1 focuses on planning parameters of a cutting fluid pump that are mainly derived from Area 2, whereas Area 3.2 states the constraints used to connect the machine tool's properties to the pump's properties.

\section{Instantiation of units and quantity kinds (Area 4)}

Every area describes a sub-system of the overall model and is therefore interlinked with the remaining three other areas. In the following, the research findings for each area and the interlinkages among these areas are explained in detail.

Our research study is based on the use case of aircraft production. The vision for air traffic-developed by the Advisory Council for Aviation Research in Europe and published under the name "Flightpath2050"—sets challenging goals for the aviation industry. By 2050, a
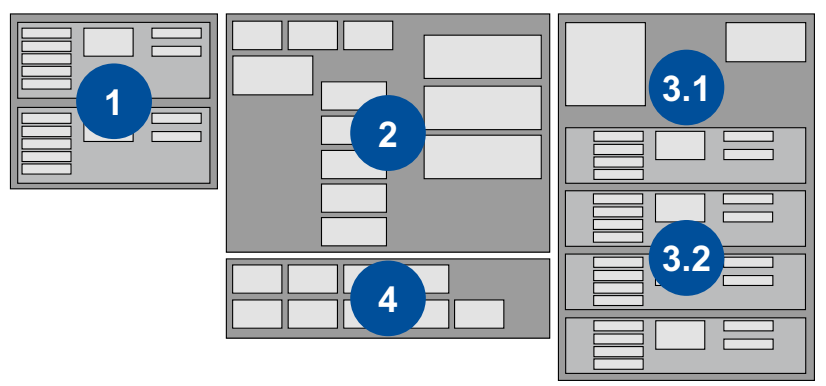

Fig. 1 SysML-model structure for the planning of a cutting fluid pump in manufacturing 
reduction of $75 \%$ in $\mathrm{CO}_{2}$ per passenger kilometre, of $90 \%$ in $\mathrm{NO}_{\mathrm{x}}$ emissions, and of $65 \%$ in noise must be fulfilled. [13] These goals pose a new challenge to aircraft and turbine engine design and thus set new requirements regarding, for instance, usable materials.

\subsection{Area 1}

Area 1 of the SysML-model (see Fig. 2) was designed to consider the interdependencies between production-based parameters and both the derived cutting fluid volume flow rate and pressure. The direct correlation is established by the fact that a machine tool has a specific need for cutting fluid for a certain production process of a particular workpiece. In this regard, we identified seven parameters from a manufacturing process, each determining the demand of cutting fluid:

1. Cutting speed $v c[\mathrm{~m} / \mathrm{min}]$

2. Cutting depth $a p[\mathrm{~mm}]$

3. Feed rate $v f[\mathrm{~m} / \mathrm{min}]$

4. Tool material $\operatorname{tm}$ (e.g. solid carbide)

5. Workpiece material wm (e.g. Inconel 718, TiAl6V4)

6. Properties of cutting fluid $c p$

7. Manufacturing process type (e.g. milling, turning)
Interdependencies between the necessary volume flow rate or pressure $(<<$ Constraint $>>$ poi $)$ on the one hand and production parameters on the other hand are modelled as constraints in parametric diagrams (see Fig. 2). The underlying rationale here is that whenever dependencies are displayed in the form of several variables, constraint and parametric diagrams help to understand the relations of all values in the system and its parts to define the impact of one parameter change. The state of a system instance at a specific time can be expressed in terms of the values of its properties. As the connection of these properties can be conveyed through equations in the constraints, the value sets form a connected network. Consequently, a change in some values leads to other value changes, which can be seen as another state of the overall system. [12, 14].

Based on the seven process parameters mentioned above, both the necessary volume flow and pressure are explicitly derived from the manufacturing process which, in turn, is determined during manufacturing systems planning.

In this context, a strongly relevant branch of the manufacturing industry is aviation where a wide variety of composite materials and alloys are used for structural components with highest quality requirements. $[15,16]$ The appropriate planning of the cutting fluid supply strategy

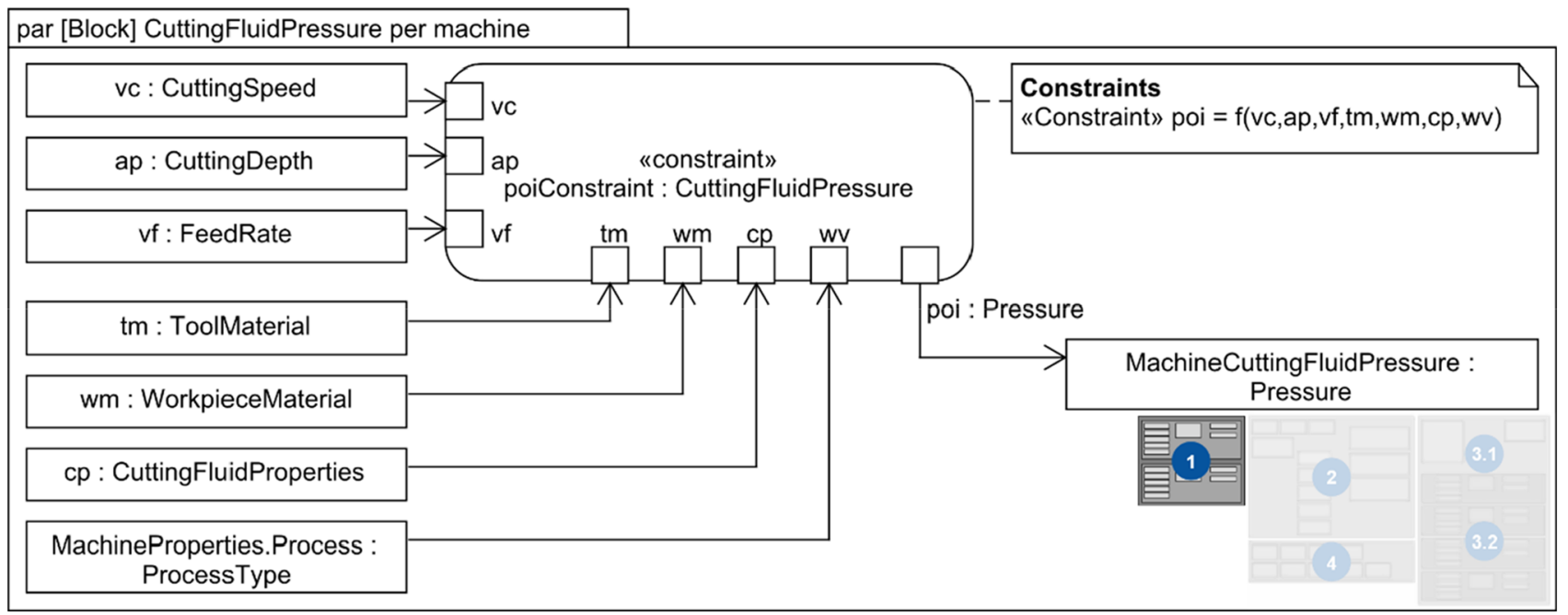

Fig. 2 Example for constraint modelling for process parameters (Area 1)

Table 1 Cases of cutting fluid supply in relation to group of material and field of application

\begin{tabular}{lllll}
\hline & Structural component & & Engine component & \\
\hline Workpiece material & Aluminium alloy & Titanium alloy & Nickel-based superalloy & Nickel-based superalloy \\
Machining process & Milling & Milling & Rough turning & Finish turning \\
Cutting fluid supply & Dry/minimal quantity & High pressure & High pressure & Flood \\
$\begin{array}{l}\text { Pressure range of cutting } \\
\text { fluid supply }\end{array}$ & 0 bar/- & 105 bar & $200-300$ bar & $1-6$ bar \\
\hline
\end{tabular}


is decisive to ensure process stability and part quality. [17, 18] For an assumed production process of aircraft components, Table 1 distinguishes between three different groups of materials often used in aviation: aluminium alloys, titanium alloys and nickel-based superalloys. The groups of material are divided into two further categories (structural component and engine component).

Structural components are characterised by the fact that they need to be both light and stable, which requires a high strength-to-weight ratio. Aluminium of the classes $2 \mathrm{xxx}, 7 \mathrm{xxx}$, and $6 \mathrm{xxx}$ - widely known for its high strengthto-weight ratio and its cost effectiveness-is therefore often used in aircraft wings, for instance in wing ribs. [19, 20] When milling these rib type components from solid blocks of aluminium, high volumes must be machined. [21] Components can also be manufactured using a titanium alloy as a substitution if they are used in temperature ranges exceeding the maximum operating temperature of aluminium. [15] In contrast to aluminium, however, titanium alloys are considered to be difficult-to-cut materials. [20, 22] The low machinability of titanium alloys, such as TiAl6V4, leads to a low material removal rate and high tool wear. Recent research efforts have shown positive effects of targeted high-pressure cutting fluid supply during milling of TiAl6V4. The cutting fluid supply strategy ensured reliable chip removal, increased tool life and higher possible material removal rates in comparison to conventional flood cooling. [23]

Safety-critical engine components pose a particular challenge in production due to the used material and the highquality requirements: The high strength-to-weight ratio of nickel-based alloys combined with the high resistance to thermal fatigue enables these materials to be used as components in aerospace engines under extreme temperature and mechanical stress. [15] Like titanium alloys, nickel-based alloys are difficult-to-cut materials because of their inherent characteristics of high hot hardness and strength. [15] Long continuous chips occur during turning rotationally symmetric parts (e.g. engine components) from nickel-based alloys like Inconel718 using flood cooling. SANGERMANN has shown that applying a high-pressure cutting fluid supply between $p=200-300$ bar during rough turning ensures steady and controllable chip breakage and eliminates the need to remove the coherent chips manually, which in the end allows for better process automation. [24]

When finish turning Inconel718, reliable chip breakage could also be achieved by high-pressure cutting fluid supply, but with the risk of inflicting uncontrollable surface damage to the already finished surface by accelerated chips. [24, 25] In this paper, we set flood cooling as the appropriate cutting fluid supply method during finish turning aeroengine components as it does not cover the risk of surface damages.
By dividing the groups of materials by their field of application and considering the existing challenges during machining these materials, four use cases of cutting fluid supply are distinguished regarding their pressure in this paper (see Table 1).

\subsection{Area 2}

Area 2 consists of individual machine tool properties (see Fig. 3). As a result of our research study, we have divided these properties into the categories of OperatingSuppliesDemand, EmissionValues (e.g. thermal radiation), EnergyDemand (e.g. nominal voltage), PositionValues (e.g. position of the machine tool in the coordinate system of the factory), and Dimensions. The connections are modelled using SysML's composition symbol which means, for instance, that 1 set of MachineProperties consists of 1 set of each of the above-mentioned categories. As shown in Fig. 3, the category OperatingSuppliesDemand is further subdivided into WaterConnection,

CompressedAir, and CuttingFluid (see $<<$ interfaceBlock $>>$ ). Volume flow rate and pressure of cutting fluid are to be read as properties of the block CuttingFluid. The pressure poi is calculated as shown in Fig. 2.

We consider the setup shown in Fig. 3 as a general framework of any manufacturing systems planning in a factory. However, since this research study focused on cutting fluid supply, a further subdivision of categories beyond CuttingFluid is not presented in Fig. 3 for the sake of transparency.

In our model, the needed pressure of, for instance, $p=105$ bar for milling titanium alloys - determined in Area 1 would be referenced by MachineCuttingFluidPressure in the block CuttingFluid.

From a factory planning point of view, Area 2 provides the individual demands of each machine tool, which are converted into a total demand in Area 3.

\subsection{Area 3}

The third area consists of parametric diagrams and constraints, and focuses on connecting the previously shown manufacturing system's properties to the cutting fluid pump's properties. Therefore, we have divided this area into two parts. Area 3.1 describes the pump's properties such as maximum available pressure and maximum available volume flow, which will be applied in Area 3.2 to evaluate the pump's performance. In the specific case of our research study, the pump's properties are associated with a screw spindle pump. The overall structure of the pump's properties is similar to the machine tool's properties. An overall assumption of this area is that all properties and constraints explained here are examples of just one pump. 


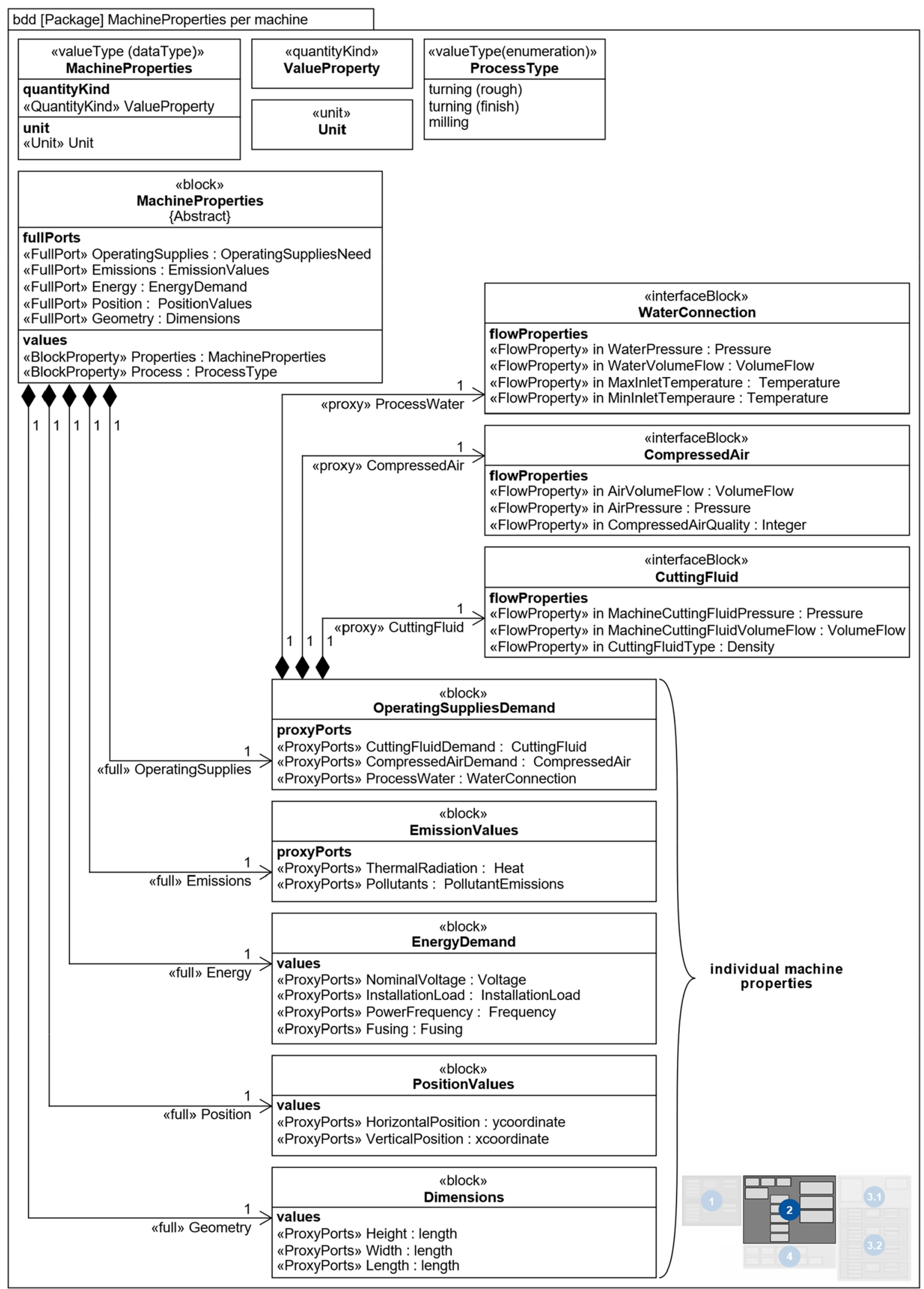

Fig. 3 Framework of machine properties in SysML for factory planning application (Area 2) 
In Area 3.2, we then compare the pump's performance data in terms of possible volume flow and pressure with the specific demand which this pump has to fulfil. To this end, the research consortium has formulated four constraints, which are shown in Fig. 4. The first two constraints determine the manufacturing system's overall demand for cutting fluid volume flow $(v n)$ and pressure $(p n)$. Whereas Area 1 determines the demand for cutting fluid on individual machine level, Area 3 aggregates the individual demands into one total requirement.

In order to give more insight regarding the conversion of input parameters to an output parameter, the following formula-specific context can be provided as an exemplary deep dive into the first constraint of RequiredPressureCuttingFluid (see in par[Block]CuttingFluidPump).

$p n=\max \left(x_{t} \cdot p o_{i} \cdot y_{i}\right)$

$p n=$ maximum pressure for cutting fluid, $p o_{i}=$ pressure demand for cutting fluid by plant $i, x_{t} \in\{0,1\}=$ demand exists at time $\mathrm{t}, y_{i} \in\{0,1\}=$ pump delivers cutting fluid to machine $i, i \in\{0, I\}=I$ machines in the factory, $t \in\{0, T\}$ $=T$ different points in time.

The maximum required pressure from the first constraint in Fig. 4 is then compared with the maximum possible pressure using the third constraint. This third constraint returns a Boolean value stating whether the pump is capable of satisfying the machine tool's demand or not (CuttingFluidPump. $p c$ : boolean). The pressure losses throughout the factory's piping system based on the theorem of Bernoulli need to be additionally considered but were not within the scope of our study.

Likewise, the volume flow generated by the pump (vcConstraint: VolumeFlowCapability) is compared with the overall factory demand for cutting fluid (vnConstraint: RequiredVolumeFlowCuttingFluid).

The maximum required volume flow cannot be determined by identifying the maximum volume flow required by one machine tool at any given time. It rather depends on the maximum of aggregated volume flows of all machines supplied by the pump at any given time.

\subsection{Area 4}

The fourth area consists of the instantiation of used value types and units, and defines the necessary physical units, which are related to the properties (see Fig. 5). By defining the units following the International System of Quantities described by ISO 80000 [26], the risk of transfer errors between different software solutions is eliminated.

With the calculation constraints, it is possible to create a direct link between the individual demands of the machine tools and the requirements for the planning of the cutting fluid pump. This makes it possible, for example, to directly detect effects of changes in the machining process on the requirements of the cutting fluid supply system at an early stage.

\section{Discussion}

The objective of the research study was to establish machinereadable parametric connections between manufacturing planning and MEP planning with a focus on cutting fluid in order to solve the problem of manually checking planning parameters in BIM-based factory planning. In the research consortium, we applied qualitative research methods and model-based systems engineering to develop a SysMLmodel for the planning of a cutting fluid pump. We chose this focus as cutting fluid ensures flawless manufacturing processes in terms of chip breaking, tool wear, process temperature and surface condition. The pump itself, however, is often planned by the MEP planner (see Sect. 1 for further explanation of the MEP domains).

The overall goal of a system design using a system engineering approach can be summarised by the phrase "Make the right system right". The message of this phrase is twofold: (1) the validation part ("Make the right system"), and (2) the verification part ("Make the system right"). Validation entails simulation approaches: System design includes incorporating the overall knowledge of the design space by describing requirements in a semi-formal way in SysML. Validating those requirements and the current understanding of the future system allows for finding open topics, required design decisions, and to prove applicability of the solution in an early design stage. Regardless of the overall systems engineering approach in use, verification checks whether the existing engineering artefacts are consistent throughout the whole model, and whether they completely describe the system. By using a semi-formal or formal approach such as SysML, the verification can be automated, i.e. the rules of the language in use and definitions in the methodology can be checked with the use of machines. The verification part has been conducted in our study. Performing simulations on our model as a validation procedure, however, will be part of future research steps. Even though the existing model can already be used as a prototype for machine-readable rule checking of cutting fluid planning, we believe that simulation results will bring the model even closer to real implementability. [14, 27]

Despite our study's requirement of high practical applicability, modelling always entails simplifications. The pressure determination mentioned in Area 3 has been simplified to show the structure of the overall SysML-model. Depending on the particular machining tasks in a factory, different 

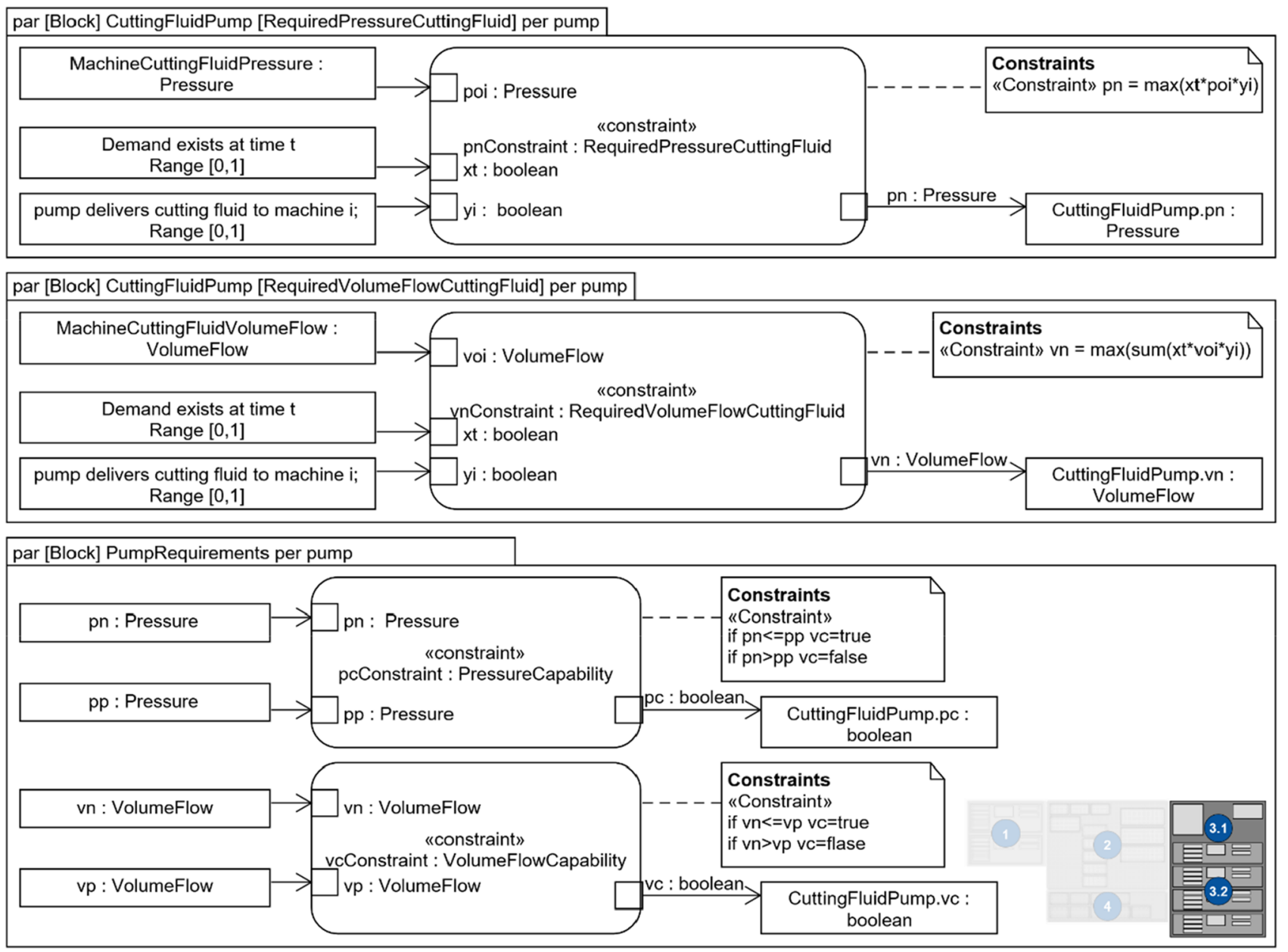

Fig. 4 Capability Constraints (Area 3.2)

cutting fluids can be used. In that case, the central supply of cutting fluid for all machine tools through one single pump might not be feasible. To alleviate this shortcoming, we inserted the variable $y_{i}$ in Area 3 to determine whether a pump supplies a specific machine tool. By using the same constraints for every pump shown in Area 3, a total demand can be calculated for more than just one pump. Additionally, one more boolean variable can be added to the machine tool properties, determining whether a machine tool requires cutting fluid supply at all. The newly added variable can then be compared to the existing $y_{i}$ variable to check whether every machine tool is connected to a pump. Furthermore, pressure losses throughout the piping system can also be taken into account. These pressure losses can be caused by pipe friction, leaks, and the structure of the piping system itself. [28] Therefore, it would be further necessary to consider the piping system's geometrical information like the layout of the piping system, and the path length from pump to machine. This information can be extracted from the MEP planner's model and then be connected to the respective calculation.
Our study has focused on aviation components and challenges derived from machining these components. We have been able to connect the MEP planning tasks to process parameters by defining four precise aviation use cases. The developed framework can also be applied in factory planning tasks even without this use-case specific limitation. To this end, we would like to emphasise the importance of Area 2 (see Fig. 3). This Area 2 can be seen as a cornerstone for adopting our results to other areas of factory planning. For instance, within the $\langle<$ block $\rangle>$ MachineProperties, we listed the energy demand of the machines. Here, an energy or electricity model can be attached which could then be used for designing a transformer. Such a model could use, inter alia, the properties we have already listed in the $\langle<$ block $\rangle>$ EnergyDemand.

Currently, the requirements of manufacturing machines are often set by subcontracted machine constructors. The success of this process largely depends on the constructor's experience. Even when requirements are not set by the manufacturing systems planner, the input from the subcontractor 


\begin{tabular}{|c|c|c|c|c|c|c|c|c|}
\hline \multicolumn{4}{|c|}{ bdd [Package] TypeDefinition } & & & & & \\
\hline \multicolumn{3}{|c|}{$\begin{array}{l}\text { «valueType (dataType)» } \\
\text { Heat }\end{array}$} & \multicolumn{3}{|c|}{$\begin{array}{l}\text { «valueType (dataType)» } \\
\text { Temperature }\end{array}$} & \multicolumn{2}{|c|}{$\begin{array}{l}\text { «valueType (dataType)» } \\
\text { RotationalSpeed }\end{array}$} & \\
\hline \multicolumn{3}{|c|}{\begin{tabular}{|l|} 
quantityKind \\
"QuantityKind» AmountOfHeatperSecond
\end{tabular}} & \multicolumn{3}{|c|}{$\begin{array}{l}\text { quantityKind } \\
\text { "QuantityKind» ThermodynamicTemperature }\end{array}$} & \multicolumn{3}{|c|}{\begin{tabular}{|l|} 
quantityKind \\
"QuantityKind» RotationalFrequency
\end{tabular}} \\
\hline \multicolumn{3}{|l|}{\begin{tabular}{|l|} 
unit \\
«Unit» Watt
\end{tabular}} & \multicolumn{3}{|c|}{\begin{tabular}{|l|} 
unit \\
«Unit» Kelvin
\end{tabular}} & \multicolumn{2}{|c|}{\begin{tabular}{|l} 
unit \\
«Unit» NumberOfTurnsPerSecond
\end{tabular}} & \\
\hline \begin{tabular}{|c|} 
"valueType (dataType)» \\
PitchDiameter
\end{tabular} & \multicolumn{3}{|c|}{$\begin{array}{l}\text { «valueType (dataType)» } \\
\text { ThreadDepth }\end{array}$} & \begin{tabular}{|c|} 
«value Type (dataType)» \\
ThreadPitch \\
\end{tabular} & \multicolumn{2}{|c|}{$\begin{array}{c}\text { "valueType (dataType)» } \\
\text { Pressure }\end{array}$} & \multicolumn{2}{|c|}{$\begin{array}{l}\text { «value Type (dataType)» } \\
\text { Length }\end{array}$} \\
\hline $\begin{array}{l}\text { quantityKind } \\
\text { "QuantityKind" Length }\end{array}$ & \multicolumn{3}{|c|}{$\begin{array}{l}\text { quantityKind } \\
\text { «QuantityKind» Length }\end{array}$} & $\begin{array}{l}\text { quantityKind } \\
\text { "QuantityKind» Length }\end{array}$ & \multicolumn{2}{|c|}{$\begin{array}{l}\text { quantityKind } \\
\text { "QuantityKind» Pressure }\end{array}$} & \multicolumn{2}{|c|}{$\begin{array}{l}\text { quantityKind } \\
\text { "QuantityKind» Length }\end{array}$} \\
\hline $\begin{array}{l}\text { unit } \\
\text { «Unit» Metre }\end{array}$ & \multicolumn{3}{|c|}{$\begin{array}{l}\text { unit } \\
\text { «Unit» Metre }\end{array}$} & \begin{tabular}{|l} 
unit \\
«Unit» Metre
\end{tabular} & \multicolumn{2}{|c|}{$\begin{array}{l}\text { unit } \\
\text { «Unit» Bar }\end{array}$} & \multicolumn{2}{|l|}{$\begin{array}{l}\text { unit } \\
\text { «Unit» Metre }\end{array}$} \\
\hline \multicolumn{2}{|c|}{$\begin{array}{l}\text { «valueType (dataType)» } \\
\text { VolumeFlow }\end{array}$} & \multicolumn{3}{|c|}{$\begin{array}{l}\text { «valueType (dataType)» } \\
\text { Density }\end{array}$} & & & \multirow{2}{*}{$\sqrt{2}$} & \multirow{2}{*}{3.1} \\
\hline \multicolumn{2}{|c|}{\begin{tabular}{|l|} 
quantityKind \\
«QuantityKind» VolumeFlowRate
\end{tabular}} & \multicolumn{3}{|c|}{$\begin{array}{l}\text { quantityKind } \\
\text { «QuantityKind» Density }\end{array}$} & & (1) & & \\
\hline \multicolumn{2}{|c|}{$\begin{array}{l}\text { unit } \\
\text { «Unit» CubicMetrePerSecond }\end{array}$} & \multicolumn{3}{|c|}{$\begin{array}{l}\text { unit } \\
\text { «Unit» KilogramPerCubicMetre }\end{array}$} & & & صة & 3.2 \\
\hline
\end{tabular}

Fig. 5 Instantiation of used valueTypes (Area 4)

can be fed into the model, thereby establishing a direct connection between machine tool properties and the design of both the manufacturing system and MEP. Here again, it can be checked whether delivered machine tool properties match the process-related machining demands.

\section{Conclusion}

This paper has shown the importance of model-based systems engineering for BIM-based factory planning. Design activities and related deliveries of geometric and especially non-geometric designs from different planning specialties require automated model checking and cannot rely solely on human capacity. In Area 2, we have shown an overall model at the interface between MEP planning and manufacturing systems planning. Area 1 and 3 have provided details on cutting fluid as one specific planning field within that interface. The overall model in Area 2 can therefore be seen as a starting point and a link for future modelling approaches that can inherit properties and attributes from our overall model.

Our research study focused on cutting fluid supply from the perspective of manufacturing machines. As next steps of our research study, we plan to

(1) extend the model to major planning domains of MEP (such as HVAC), and

(2) further refine the current model with regard to cutting fluid supply.
Beyond cutting fluid, the main MEP planning domains such as electricity or HVAC should be analysed and integrated into the model to create a holistic approach for automated rule checking within the MEP-manufacturing interface. For instance, the model could be enhanced by implementing the calculation of necessary total cooling loads based on thermal radiation during manufacturing processes.

We will then create a use case where we can validate the content of our holistic interface model according to the system engineering approach (see Sect. 4).

Another stream of research that follows from our study is to investigate an innovative cutting fluid supply: Using a high-pressure cutting fluid supply when turning components ensures controllable chip breakage, but at the same time increases the risk of surface damage to already finished surfaces. By supplying a high-pressurised but pulsating cutting fluid stream, the advantages of high-pressure supply could be exploited without risking surface damage. Furthermore, by changing the pressure in alternating time intervals, less energy and less cutting fluid could be consumed. This not only has economical advantages but also environmental benefits as cutting fluid is considered harmful to the environment. [29]

We are convinced that connecting machine tool properties to MEP planning tasks, such as the planning of a cutting fluid pump, is a first step to enable automatic validation of BIM-based factory designs in the future. 
We have developed a SysML-model representing the underlying logic for creating a software-specific architecture and code. Our approach is therefore to be seen as the basis for software code that can be written for plug-ins for software like Autodesk Revit (e.g. via the Revit API). Another possibility to implement our approach would be to stay within the domain of Systems Modelling and to import instances from the Building Information Model into our SysML-model. This can be achieved, for example, by using the ModelCenter MBSE within the PTC Integrity Modeler. Values and non-numeric properties can be exported from the Building Information Model (if no direct interface is implemented), and loaded into the SysML-model as concrete instances which could then be checked internally within the SysML-model. The general concept of BIM is therefore enhanced by an unambiguous representation of parametric connections between objects and planning information on a system level which can be implemented by either coding a plug-in for existing software or by extracting project information from the Building Information Model and checking them internally using Systems Modeling software.

These implementation options also create independence from specific data formats (e.g..ifc) since the BIM-software either directly checks the planning information-using the plug-in based on our approach-or exports to, for example, Microsoft Excel.

As for the integration of the IFC information model (Industry Foundation Classes), it has to be noted that our SysML-model would have to follow the naming conventions of the IFC information model, or would need a mapping between the different types of naming. However, the IFC4 PropertySet within the bsDD (buildingSMART Data Dictionary) does currently not provide sufficient expressivity regarding cutting fluid pump properties, or pump properties at all [30].

Funding Open Access funding enabled and organized by Projekt DEAL.

Open Access This article is licensed under a Creative Commons Attribution 4.0 International License, which permits use, sharing, adaptation, distribution and reproduction in any medium or format, as long as you give appropriate credit to the original author(s) and the source, provide a link to the Creative Commons licence, and indicate if changes were made. The images or other third party material in this article are included in the article's Creative Commons licence, unless indicated otherwise in a credit line to the material. If material is not included in the article's Creative Commons licence and your intended use is not permitted by statutory regulation or exceeds the permitted use, you will need to obtain permission directly from the copyright holder. To view a copy of this licence, visit http://creativecommons.org/licenses/by/4.0/.

\section{References}

1. Burggräf P, Dannapfel M, Ebade Esfahani M et al (2019) Integrated factory modelling: using bim to disrupt the interface between manufacturing and construction in factory planning. In: de Wilde WP, Mahdjoubi L, Garrigós AG (eds) Building information modelling (BIM) in design, construction and operations III. WIT Press, Southampton, pp 143-155

2. Burggräf P, Dannapfel M, Ebade Esfahani M et al (2020) How to improve collaboration efficiency in the built environment of factories by using an integrated factory modelling concept-An expert study. IJDNE 15:473-481. https://doi.org/10.18280/ijdne .150403

3. Schuh G, Kampker A, Wesch-Potente C (2011) Condition based factory planning. Prod Eng Res Devel 5:89-94. https://doi. org/10.1007/s11740-010-0281-y

4. Nyhuis P, Wulf S, Klemke $T$ et al (2010) Integrative factory, technology, and product planning-systemizing the information transfer on the operational level. Prod Eng Res Devel 4(23):231-237. https://doi.org/10.1007/s11740-010-0225-6

5. Bergs T, Hermann L, Rey J et al (2020) Methodology for the identification of alternative manufacturing changes for safety-critical components. Prod Eng Res Devel. https://doi. org/10.1007/s11740-020-00960-1

6. Braun V, Clarke V (2013) Successful qualitative research: a practical guide for beginners. First published, SAGE, Los Angeles, London, New Delhi

7. Döring N, Bortz J (2016) Forschungsmethoden und Evaluation in den Sozial- und Humanwissenschaften. Springer, Berlin, Heidelberg

8. Hsieh H-F, Shannon SE (2005) Three approaches to qualitative content analysis. Qual Health Res 15:1277-1288. https://doi. org/10.1177/1049732305276687

9. Batt T (2013) Systems-Engineering mit der SysML: Wichtige Diagramme, Notationen und Anwendungen im Überblick. In: Tagungsband / Embedded Software Engineering Kongress 2013, 2. bis 6. Dezember 2013, Sindelfingen. Elektronikpraxis/ Vogel; MicroConsult Microelectronics Consulting \& Training GmbH, Würzburg, München, pp 112-124

10. Object Management Group (2005) Introduction to OMG's unified modeling language. https://www.uml.org/what-is-uml.htm. Accessed 25 May 2020

11. sysML Forum (2020) What is SysML? What you need to know. https://sysmlforum.com/. Accessed 26 May 2020

12. Object Management Group (2019) OMG systems modeling language: Version 1.6. https://www.omg.org/spec/SysML

13. European Commission (2011) Flightpath 2050: Europe's vision for aviation; maintaining global leadership and serving society's needs; report of the high-level group on aviation research. Policy/European Commission. Publications Office of the European Union, Luxembourg

14. Korff A, Schacher M (2008) Modellierung von eingebetteten Systemen mit UML und SysML. Spektrum Akad. Verl, Heidelberg

15. Ezugwu EO, Bonney J, Yamane Y (2003) An overview of the machinability of aeroengine alloys. J Mater Process Technol 134:233-253. https://doi.org/10.1016/S0924-0136(02)01042-7

16. M'Saoubi R, Axinte D, Soo SL et al (2015) High performance cutting of advanced aerospace alloys and composite materials. CIRP Ann 64:557-580. https://doi.org/10.1016/j.cirp.2015.05.002

17. Madanchi N, Kurle D, Winter M et al (2015) Energy efficient process chain: the impact of cutting fluid strategies. Procedia CIRP 29:360-365. https://doi.org/10.1016/j.procir.2015.02.056

18. Klocke F, Sangermann H, Krämer A et al (2011) Influence of a high-pressure lubricoolant supply on thermo-mechanical tool load 
and tool wear behaviour in the turning of aerospace materials. Proc Inst Mech Eng, Part B: J Eng Manufac 225:52-61. https:// doi.org/10.1177/09544054JEM2082

19. Yashpal, Jawalkar CS, Kant S (2015) A review on use of aluminium alloys in aircraft components. JMS 3:33-38. https://doi. org/10.26634/jms.3.3.3673

20. Santos MC, Machado AR, Sales WF et al (2016) Machining of aluminum alloys: a review. Int J Adv Manuf Technol 86:30673080. https://doi.org/10.1007/s00170-016-8431-9

21. Aerospace Manufacturing (2019) Manufacturing wing ribs the right way. https://www.aero-mag.com/manufacturing-wing-ribsthe-right-way/. Accessed 20 Apr 2020

22. Ezugwu EO (2005) Key improvements in the machining of difficult-to-cut aerospace superalloys. Int J Mach Tools Manuf 45:1353-1367. https://doi.org/10.1016/j.ijmachtools.2005.02.003

23. Lakner T, Peng B, Klocke F Schullbericht zu IGF-Vorhaben Nr. 18401 N: Steigerung der Produktivität beim Fräsen durch zielgerichtete Zufuhr des Kühlschmierstoffs mit Hochdruck-ProMill

24. Sangermann H (2013) Hochdruck-Kühlschmierstoffzufuhr in der Zerspanung. Zugl.: Aachen, Techn. Hochsch., 2013, 1. Aufl. Edition Wissenschaft, vol 2013,19. Apprimus-Verl., Aachen

25. Cayli T (2018) Surface anomalies in turning of difficult-to-cut materials with high-pressure coolant supply, 1st edn. Apprimus Wissenschaftsverlag, Aachen
26. International Organization for Standardization (2009) Quantities and units - Part 1: General (ISO 80000-11:2009+Cor 10:2011) (ISO 80000-1)

27. Walden DD, Roedler GJ, Forsberg K et al (eds) (2015) Systems engineering handbook: a guide for system life cycle processes and activities; INCOSE-TP-2003-002-04, 2015, 4th edn. Wiley, Hoboken, NJ

28. Helbing KW, Mund H, Reichel M (2014) Handbuch Fabrikprojektierung. Springer, Berlin, Heidelberg

29. Bergs T, Splettstosser A, Schraknepper D (2019) Pulsating highpressure cutting fluid supply for chip control in finish turning of inconel. MM SJ 718:3200-3205

30. Pset_PumpTypeCommon. In: buildingSMART Data Dictionary. http://bsdd.buildingsmart.org/\#concept/browse/2v_wA0qV uHuO00025QrE\$V

Publisher's Note Springer Nature remains neutral with regard to jurisdictional claims in published maps and institutional affiliations. 